\title{
Vitamin D 1 Alpha-Hydroxylase Deficiency
}

National Cancer Institute

\section{Source}

National Cancer Institute. Vitamin D 1 Alpha-Hydroxylase Deficiency. NCI Thesaurus.

Code C131073.

An autosomal recessive form of rickets caused by inactivating mutation(s) in the CYP27B1 gene, encoding 25-hydroxyvitamin D-1 alpha hydroxylase, the renal enzyme that converts 25-hydroxyvitamin D to 1 alpha,25-dihydroxyvitamin $D$ (calcitriol), the active metabolite of vitamin $\mathrm{D}$ (cholecalciferol). The condition is characterized by reduced serum concentrations of 1 alpha,25-hydroxyvitamin D, normal concentrations of 25hydroxyvitamin D, increased serum alkaline phosphatase, hypocalcemia due to reduced intestinal calcium absorption, hypophosphatemia due to renal phosphate wasting, secondary hyperparathyroidism, rickets, seizures, muscle weakness and failure to thrive. 